\title{
CARACTERÍSTICAS FÍSICAS E QUÍMICAS DE FRUTOS DE PUPUNHEIRA NO ESTADO DO PARÁ ${ }^{1}$
}

\author{
ANA VÂNIA CARVALHO ${ }^{2}$, JACQUELINE CHAVES BECKMAN ${ }^{3}$ \\ RENAN DE ALMEIDA MACIEL ${ }^{4}$, JOÃO TOMÉ DE FARIAS NETO 5
}

RESUMO- O objetivo deste estudo foi caracterizar física e físico-quimicamente frutos de 21 matrizes de pupunheira (Bactris gasipaes Kunth), visando a obter subsídios que permitam avançar com o programa de melhoramento genético, em especial para características da polpa do fruto. Os frutos provenientes de diferentes genótipos foram caracterizados quanto à dimensão dos frutos e caroço, umidade, proteínas, lipídeos, cinzas, fibras e carotenoides totais. Os resultados obtidos para as diferentes variáveis analisadas demonstraram diferenças entre os frutos obtidos de diferentes genótipos. A análise de proteínas apresentou valores que variaram de 4,20 a 6,79\%, com destaque para a matriz B04-P20, que apresentou o maior valor. Para lipídeos, os teores variaram bastante, com valores entre 8,25 e 40,83\%, destacando-se a matriz B02-P30 com o maior teor de lipídeos. Os teores de carotenoides totais das matrizes de pupunheira variaram de 8,02 a $124,90 \mu \mathrm{g} / \mathrm{g}$, com destaque para as matrizes B02-P30 $(124,90 \mu \mathrm{g} / \mathrm{g})$ e B05-P45 $(123,04 \mu \mathrm{g} / \mathrm{g})$, indicando que a pupunha pode contribuir de maneira importante na ingestão de antioxidantes na dieta. De maneira geral, as análises físicas e físico-químicas dos frutos mostraram diferenças significativas entre as matrizes para os caracteres estudados, evidenciando ser um conjunto geneticamente promissor para a prática da seleção. Termos para indexação: Bactris gasipaes Kunth, caracterização físico-química, carotenoides.

\section{PHYSICAL AND CHEMICAL CHARACTERISTICS OF PEACH PALM FRUITS IN THE STATE OF PARÁ}

\begin{abstract}
The aim of this study was to assess the physical and physical-chemical characteristics of the fruits of 21 reproductive peach palms to help guide future research on genetic improvements of the species, especially regarding the fruit pulp. Fruits from each genetic material were characterized by fruit and seed size, moisture, protein, lipid, ash, fiber and total carotenoids. Average values for all studied variables were significantly different among all individuals. Protein values ranged from 4.20 to $6.79 \%$, especially for B04-P20 that showed the highest value. Lipid levels varied markedly, with values ranging between 8.25 and $40.83 \%$, and matrix B02-P30 presenting the greatest levels of lipids. Total carotenoids ranged from 8.02 to $124.90 \mathrm{mg} / \mathrm{g}$, with matrices B02-P30 $(124.90 \mu \mathrm{g} / \mathrm{g})$ and B05-P45 $(123.04 \mu \mathrm{g} / \mathrm{g})$ presenting the highest values. The high total carotenoid values observed indicates that peach palms could make a significant contribution to antioxidants in the diet. Overall, the physical and physical-chemical assessment revealed significant differences among the studied reproductive individuals for the characters studied, indicating that this species offers considerable promise for future research on genetic improvements.
\end{abstract}

Index terms: Bactris gasipaes Kunth, physical-chemical characterization, carotenoids.

\footnotetext{
'Trabalho 180-13). Recebido em: 14-05-2013. |Aceito para publicação em: 06-09-2013

${ }^{2}$ Agrônoma, Pesquisadora da Embrapa Amazônia Oriental, Av. Dr. Enéas Pinheiro, s/n - Marco. CEP: 66095-100, Belém-PA. E-mail: ana-vania.carvalho@embrapa.br

${ }^{3}$ Aluna do curso de Engenharia de Alimentos da Universidade Federal do Pará. E-mail: jacque_beckman@hotmail.com.

${ }^{4}$ Aluno do curso de mestrado em Ciência e Tecnologia de Alimentos da Universidade Federal do Pará. E-mail: renan.maciel@hotmail.com

${ }^{5}$ Agrônomo, Pesquisador da Embrapa Amazônia Oriental. E-mail: joao.farias@embrapa.br
} 


\section{INTRODUÇÃO}

A pupunheira (Bactris gasipaes Kunth, Palmae) é uma fruteira nativa da Amazônia que apresenta ampla diversidade genética em suas populações silvestres e domesticadas, devido aos seus diferentes estádios de domesticação, locais de cultivo e por atender a diversas preferências humanas em termos de sabor, uso, processamento e até cor (CLEMENT;SANTOS, 2002; SANTOS et al., 2011).

A pupunheira pode ser cultivada com finalidades distintas: para fruto e para palmito. Na Amazônia brasileira, a pupunheira é cultivada quase exclusivamente para fruto, principalmente por agricultores de baixa renda. $\mathrm{O}$ fruto, quando maduro, possui um epicarpo fibroso que varia de cor, podendo ser vermelha, laranja ou amarela, e um mesocarpo que varia de amiláceo a oleoso, com um endocarpo envolvendo uma amêndoa fibrosa e oleosa. O principal uso do fruto é na forma inteira, como parte do lanche ou do café de manhã. Eles apresentam elevado valor nutritivo sendo ricos em lipídeos, fibras, amido e carotenóides totais, que dão à sua polpa, além de uma intensa coloração amarela, um apelo funcional bastante significativo; além disso, apresenta elevado valor energético (YUYAMA; COZZOLINO, 1996; CARVALHO et al., 2009).

Os carotenoides são considerados substâncias antioxidantes, e seu estudo nos últimos anos tem revelado um grande interesse, principalmente nos efeitos das espécies reativas nos sistemas biológicos. Em sistemas biológicos, as espécies redoxiativas são formadas naturalmente ou devido a alguma alteração fisiológica. Elas estão envolvidas em muitos processos fisiológicos importantes, tais como: produção de energia, fagocitose, regulação do crescimento celular, sinalização celular e síntese de substâncias. Entretanto, o excesso de radicais livres pode gerar efeitos prejudiciais, podendo ser a etiologia e/ou patogênese de várias patologias, como câncer, catarata, doenças cardiovasculares e neurodegenerativas, entre outras (BERG et al., 1999). Porém, estudos revelam que os antioxidantes naturais de frutas e hortaliças fornecem proteção e reduzem os danos causados pelos processos oxidativos no organismo. As pesquisas com antioxidantes naturais têm crescido em importância tanto no aspecto do conhecimento dos benefícios como com o objetivo de aumentar a qualidade dos alimentos (HASSIMOTTO et al., 2005; WANG; PRIOR, 1996).

Diversos estudos têm detectado diferenças genéticas para caracteres físicos e físico-químicos entre genótipos de pupunheira (CARVALHO et al., 2009; FERREIRA; PENA, 2003; OLIVEIRA et al., 2007), fato que abre a possibilidade de sucesso na seleção para alterar esses caracteres. Vale salientar que a identificação e a seleção de material genético com elevada qualidade, que produza frutos com boas características físicoquímicas, apropriado à comercialização e adaptado às condições locais, é de grande importância para a cultura da pupunheira. Além disso, a caracterização qualitativa e quantitativa é, hoje, no mundo, uma demanda relevante, principalmente em relação a espécies de importância econômica atual e potencial como a pupunha (CARVALHO et al., 2009).

Neste contexto, o presente estudo objetiva a caracterização física e físico-química de frutos de pupunheira de diferentes matrizes, coletados no Estado do Pará, a fim de colher subsídios que permitam avançar com o programa de melhoramento genético, em especial para características da polpa do fruto.

\section{MATERIAL E MÉTODOS}

Os frutos foram coletados de 21 diferentes matrizes de pupunheira (Bactris gasipaes Kunth), situadas em experimento estabelecido no município de Tomé-Açu, no nordeste paraense, localizado a $2^{\circ} 24^{\prime} 50.83^{\prime}$ ' S, 48 $08^{\prime} 59.77^{\prime}$ 'W. O clima é quente e úmido, e a precipitação pluviométrica é caracterizada por dois períodos distintos de chuvas, um de dezembro a maio, com índices superiores a $150 \mathrm{~mm} /$ mês, onde se concentram cerca de $80 \%$ do total anual de precipitação, e outro, de junho a novembro, com índice variando de $49 \mathrm{~mm}$ a $105 \mathrm{~mm}$. As matrizes analisadas receberam codificações em função da distribuição no campo, sendo separadas em blocos (B) e plantas (P): B01-P09, B01-P34, B01-P44, B01-P46, B02-P14, B02-P30, B02-P33, B02-P42, B04-P20, B05-P06, B05-P14, B05-P15, B05-P26, B05-P45, B05-P45, В06-P02, B07-P48, B08-P33, $\mathrm{B} 09-\mathrm{P} 07, \mathrm{~B} 09-\mathrm{P} 17$ e B10-P03. Todos os frutos foram colhidos no mesmo dia.

Os frutos foram caracterizados fisicamente de acordo com as seguintes determinações:

- Dimensões do fruto (comprimento e iâmetro): utilizou-se um paquímetro, sendo as medições realizadas em 40 frutos.

- Dimensões do caroço (comprimento e diâmetro): utilizou-se de um paquímetro, sendo as medições realizadas em 40 caroços.

- Massa média por fruto: aferiu-se a massa de 40 frutos, calculando-se a seguir a massa média por fruto.

-Massa média por caroço: aferiu-se a massa de 40 caroços, calculando-se a seguir a massa média 
por caroço.

Após descascamento, as polpas dos frutos de pupunha foram caracterizadas quanto aos teores de umidade, cinzas, proteínas e lipídeos, de acordo com a metodologia descrita por AOAC (1997), teor de fibras (método de detergência, segundo GOERING; VAN SOEST, 1970) e carotenoides totais, segundo metodologia descrita por Godoy e RodriguezAmaya (1994). Todas as análises foram realizadas em triplicata.

Os resultados das características avaliadas foram submetidos à análise de variância e, considerando-se as significâncias dos quadrados médios, foi analisado o desempenho das médias das matrizes para cada caráter, empregando-se o agrupamento de médias de Scott-Knott, a 5\% de probabilidade, utilizando-se do software GENES (CRUZ, 2006).

\section{RESULTADOS E DISCUSSÃO}

Os resultados obtidos para as características físicas dos frutos de 21 matrizes de pupunheira estão apresentados na Tabela 1. De acordo com a análise estatística, para os seis caracteres físicos estudados, houve a formação de números distintos de grupos, indicando a capacidade diferenciadora de alguns caracteres em discriminar divergências genéticas entre as matrizes. Em ordem decrescente de formação de grupos, temos: sete grupos (a até g) para o caráter comprimento dos frutos; seis grupos (a até f) para diâmetro dos frutos; cinco grupos (a até e) para massa dos frutos; cinco grupos (a até e) para comprimento dos caroços; cinco grupos (a até e) para massa dos caroços e quatro grupos(a até d) para comprimentos dos caroços. Portanto, comprimento e diâmetro dos frutos podem ser considerados os melhores caracteres físicos para representar a diversidade genética entre as matrizes.

Para a massa dos frutos, observaram-se valores variando entre 16,06 e 39,17g, destacando-se as matrizes B01-P09, B01-P34, B02-P42 e B04-P20, que apresentaram os frutos com os maiores valores. O resultado obtido neste trabalho está de acordo com os valores encontrados por Ferreira e Pena (2003), em estudo sobre comportamento higroscópico da farinha de pupunha, que observaram massa média de 30,6 g para frutos de pupunheira.

Os valores verificados para o comprimento dos frutos variaram de 29,72 a 51,27 mm, e os frutos da matriz B04-P20 apresentaram o maior valor médio $(51,27 \mathrm{~mm})$. Ferreira e Pena (2003) observaram valores para o comprimento de frutos de pupunheira entre 31 e $49 \mathrm{~mm}$, valores próximos aos observados neste trabalho.

Quanto ao diâmetro, os frutos apresentaram valores mínimo e máximo de 24,18 $\mathrm{mm}$ e 49,08 $\mathrm{mm}$, respectivamente, valores contemplados na faixa observada por Ferreira e Pena (2003) de 34 a 38 mm.

Observou- se que os frutos pertencentes às matrizes B02-P33, B04-P20 e B05-P26 não apresentavam caroços (Tabela 1). Já para frutos com caroços, destacou-se a matriz B08-P33 com os caroços apresentando as maiores massa e dimensão.

$\mathrm{Na}$ Tabela 2, são apresentados os resultados da caracterização físico-química e o teor de carotenoides totais dos frutos de 21 matrizes de pupunheira. De acordo com a análise estatística, para os seis caracteres físico-químicos estudados, também houve a formação de números distintos de grupos, indicando a capacidade diferenciadora de alguns caracteres em discriminar divergências genéticas entre as matrizes. Em ordem decrescente de formação de grupos, temos: dezesseis grupos (a até p) para o caráter lipídeos; onze grupos (a até k) para umidade; dez grupos (a até j) para carotenoides; sete grupos (a até g) para proteína; seis grupos (a até f) para fibras e quatro grupos(a até d) para cinzas. Portanto, lipídeos, umidade e carotenoides foram os melhores caracteres físico-químicos para representar a diversidade genética entre as matrizes.

Para a umidade, observaram-se resultados variando de 43,9 a $65,39 \%$, sendo que a matriz B01-P09 apresentou o maior valor de umidade. Ferreira e Pena (2003), estudando o comportamento higroscópico da farinha de pupunha, observaram valor de $68,5 \%$ para os frutos in natura, e Andrade et al. (2003) verificaram umidade média de 46,0\% para polpa de pupunha in natura da raça Solimões.

Com relação aos teores proteicos encontrados, 4,20 a $6,79 \%$, os mesmos foram próximos daqueles observados por Yuyama et al. (2003), entre 3,83 e $5,35 \%$ base seca, em estudo sobre os frutos de três populações de pupunheira cultivadas na Amazônia Central do Brasil, e por Andrade et al. (2003), que observaram $2,41 \%$ de proteínas na polpa de pupunha da raça Solimões. Já Carvalho et al. (2009) e Oliveira et al. (2007) verificaram teores proteicos de $4,15 \%$ e $5,7 \%$, respectivamente, em farinha de pupunha, valores próximos aos verificados neste estudo.

Para a análise de lipídeos, os teores variaram bastante, com valores entre 8,25 e $40,83 \%$, destacando-se a matriz B02-P30 com o maior teor de lipídeos. Ferreira e Pena (2003), em estudo sobre o comportamento higroscópico da farinha de pupunha, observaram teor de lipídeo variando entre $6,1 \%$ e 9,8\%. Já Carvalho et al. (2009) e Oliveira et al. (2007) relataram valores de $11,56 \%$ e $10,3 \%$ de 
lipídeos, respectivamente, em estudo sobre a farinha de pupunha.

Com relação ao teor de cinzas dos frutos analisados, verificou-se variação entre 1,08 e 2,54\% (Tabela 2). Esses valores estão próximos dos relatados na literatura, em que se verificam teores variando de 1,33 a 2,20\% (ANDRADE et al., 2003; CARVALHO et al., 2009; OLIVEIRA et al., 2007).

Para as fibras totais, os valores variaram entre 0,87 e $3,4 \%$ (Tabela 2). Vale ressaltar que os frutos foram analisados com a casca, ou seja, polpa mais casca, o que favorece o incremento dos teores de fibras totais. Andrade et al. (2003), estudando a polpa de frutos in natura de pupunha da raça Solimões, observaram teor de fibra total de $1,41 \%$, valor dentro da faixa observada neste trabalho. Já Yuyama (2003) observou variação de 11,95 a 17,23\% de fibras em frutos de três populações de pupunheiras cultivadas na Amazônia Central do Brasil, valores superiores aos observados neste trabalho.

Os frutos de pupunha possuem polpa com coloração que vai do amarelo ao laranja, o que indica que os carotenóides são os pigmentos predominantes. No presente trabalho, observaram-se teores de carotenoides totais variando de 8,02 a $124,90 \mu \mathrm{g} / \mathrm{g}$, com destaque para as matrizes B02-P30 $(124,90 \mu \mathrm{g} / \mathrm{g})$ e B05-P45 $(123,04 \mu \mathrm{g} / \mathrm{g})$, o que indica tais matrizes como promissoras para seleção nos trabalhos de melhoramento genético, visando a obter frutos com maiores teores de carotenoides totais.

Andrade et al. (2003), estudando frutos de pupunheira, observaram teores de $24,60 \mu \mathrm{g} / \mathrm{g}$ na polpa de pupunha in natura e $47,10 \mu \mathrm{g} / \mathrm{g}$ na pupunha cozida. Já Carvalho et al. (2009) relataram teor de carotenoides totais para a farinha de pupunha de $137,98 \mu \mathrm{g} / \mathrm{g}$, valor superior ao observado neste trabalho. Segundo Andrade et al. (2003), ocorrem mudanças químicas nesses pigmentos por ocasião do cozimento, provavelmente pela descomplexação de carotenoides, o que reflete na intensificação da coloração alaranjada e aumento do teor de carotenoides totais na pupunha cozida.

TABELA 1- Valores médios de comprimento, diâmetro e massa do fruto e caroço, referentes a frutos de 21 matrizes de pupunheira. Embrapa Amazônia Oriental, 2013.

\begin{tabular}{|c|c|c|c|c|c|c|}
\hline \multicolumn{4}{|c|}{ Fruto } & \multicolumn{3}{|c|}{ Caroço } \\
\hline Matriz & $\begin{array}{c}\text { Comprimento } \\
\text { (mm) }\end{array}$ & $\begin{array}{c}\text { Diâmetro } \\
\text { (mm) }\end{array}$ & Massa (g) & (mm) & $\begin{array}{l}\text { Diâmetro } \\
\text { (mm) }\end{array}$ & $\begin{array}{c}\text { Massa } \\
\text { (g) }\end{array}$ \\
\hline B01-P09 & $40,20 \pm 1,72 c$ & $38,24 \pm 2,00 b$ & $39,06 \pm 5,93 \mathrm{a}$ & $18,19 \pm 1,19 b$ & $15,00 \pm 0,78 \mathrm{c}$ & $2,54 \pm 0,21 d$ \\
\hline B01-P34 & $38,25 \pm 2,03 d$ & $7,82 \pm 1$ & $36,13 \pm$ & & $18,16 \pm 0,72 \mathrm{a}$ & $3,73 \pm$ \\
\hline & $32,18 \pm 1,68 f$ & $36,62 \pm 1$ & $28,08 \pm$ & & $60 \mathrm{a}$ & \\
\hline B01-P46 & $31,47 \pm$ & $33,60 \pm$ & $23,79=$ & & & $2,47 \pm 0,43 d$ \\
\hline B02-P14 & $35,95 \pm$ & $34,91 \pm$ & $27,29 \pm$ & & 13,7 & $1,61 \pm 0,28 \mathrm{e}$ \\
\hline & 38,1 & & 24,9 & & 15,1 & \\
\hline & & & & - & - & 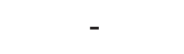 \\
\hline B02-P42 & 47,36 & 49,08 & 36,6 & $16,91 \pm$ & $17,74 \pm 0$ & $3,67 \pm 0,40 b$ \\
\hline B04-P20 & 51,2 & & & - & - & - \\
\hline B05- & 41,3 & 26,76 & & 19,4 & $15,39 \pm 1$ & $2,91 \pm 1,01 \mathrm{c}$ \\
\hline B05-P14 & 34,97 & $12 d$ & 25, & & 12,32 & $1,49 \pm 0,28 \mathrm{e}$ \\
\hline & & & & & & \\
\hline & $41,60 \pm 1$ & $28,66=$ & 22,0 & - & - & - \\
\hline B05-P30 & $36,05 \pm 1,47 \mathrm{e}$ & $35,20 \pm 1,65 c$ & $25,60 \pm 3,19 d$ & $27 \pm 1,03 \mathrm{a}$ & $16,85 \pm 1,03 b$ & $3,47 \pm 0,39 b$ \\
\hline B05-P45 & $37,51 \pm 2,32 d$ & & $28,36 \pm 3,42 \mathrm{c}$ & & $16,68 \pm 0$ & $3,55 \pm 0,34 b$ \\
\hline B06-P02 & $34,94 \pm 2,10 \mathrm{e}$ & $31,99 \pm 1,56 \mathrm{~d}$ & $25,69 \pm 2,71 d$ & & $\pm 0,64 \mathrm{e}$ & $1,41 \pm 0,18 \mathrm{e}$ \\
\hline B07-P48 & $36,90 \pm 1,86 d$ & & $31,22 \pm 3,9$ & $16,93 \pm 0$ & & $2,06 \pm 0,27 d$ \\
\hline & $32,68 \pm 3,69 f$ & $35,36 \pm 3,87 \mathrm{c}$ & $34,301 \pm 6,13 b$ & & $18,33 \pm 1,51 \mathrm{a}$ & $4,50 \pm 0,90 \mathrm{a}$ \\
\hline B09-P07 & $42,32 \pm 1,46 c$ & $34,34 \pm 0,96 \mathrm{~d}$ & $32,62 \pm 2,01 b$ & $20,75 \pm 1,56 a$ & $15,95 \pm 1,41 b$ & $3,33 \pm 0,89 b$ \\
\hline B09-P17 & $35,68 \pm 2,18 \mathrm{e}$ & $32,23 \pm 2,31 d$ & $22,73 \pm 3,64 d$ & $16,53 \pm 0,45 c$ & $15,14 \pm 0,95 \mathrm{c}$ & $2,47 \pm 0,44 d$ \\
\hline B10-P03 & $29,72 \pm 1,66 \mathrm{~g}$ & $29,29 \pm 1,48 \mathrm{e}$ & $29,34 \pm 2,47 \mathrm{c}$ & $18,72 \pm 1,00 b$ & $16,43 \pm 0,86 b$ & $3,40 \pm 0,28 b$ \\
\hline
\end{tabular}

Na coluna, médias seguidas de mesma letra pertencem a um grupo comum, de acordo com o critério de agrupamento de Scott-Knott $(\mathrm{P}<0,05)$.

Matrizes B02-P33, B0-P20 e B05-P26 não apresentaram caroços (frutos sem caroços). 


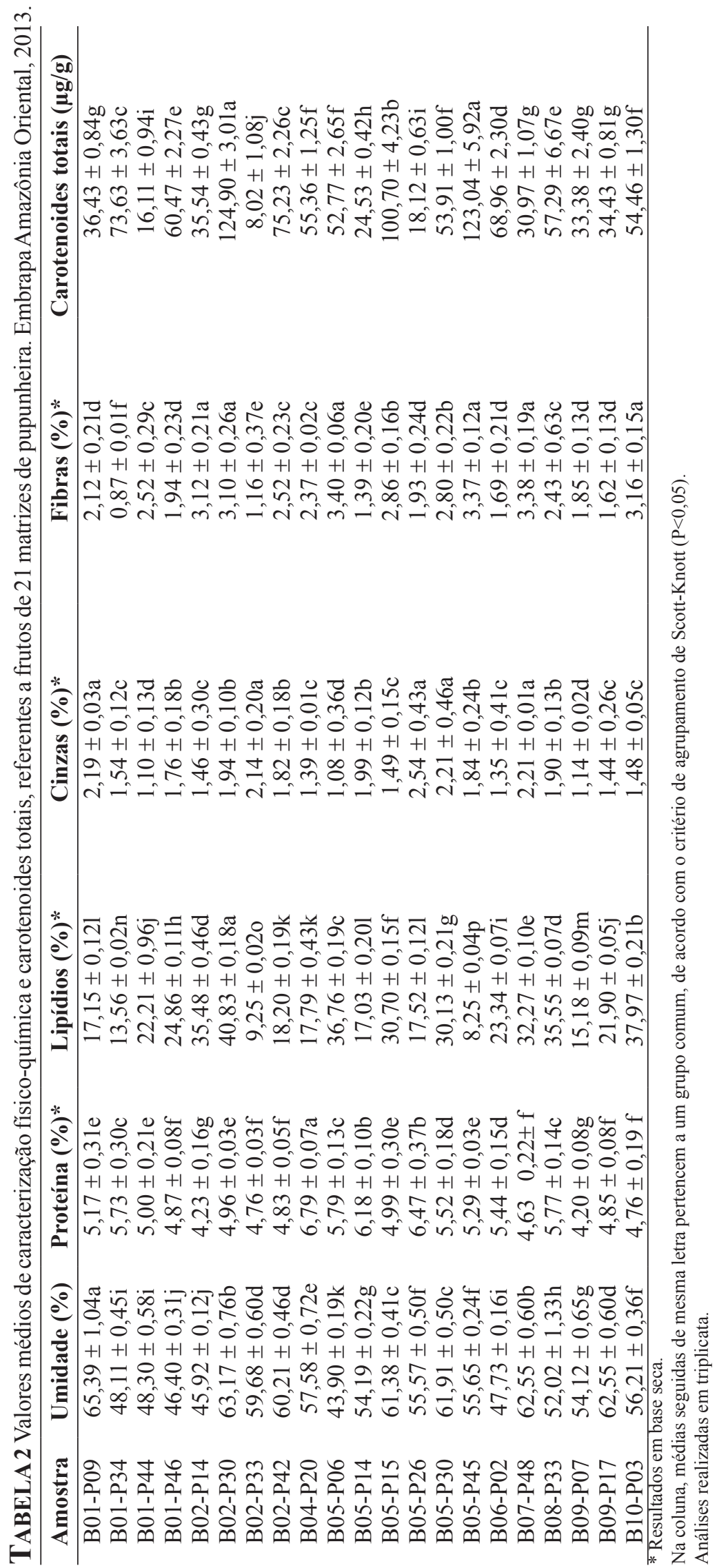




\section{CONCLUSÕES}

1-As análises físicas e físico-químicas dos frutos mostram diferenças significativas entre as matrizes para os caracteres estudados, evidenciando ser um conjunto geneticamente promissor para a prática da seleção.

2-Através dos resultados obtidos, é possível discriminar matrizes com características específicas. $\mathrm{Se}$ o interesse do melhoramento for por frutos sem caroço, merecem destaque as matrizes B02-P33, B04-P20 e B05-P26. Já para a característica teor de lipídeos, a matriz B02-P30 apresentou o maior valor para essa variável. Com relação aos carotenoides totais, as matrizes B02-P30 e B05-P45 apresentaram os maiores teores. Já a matriz B04-P20 apresentou o maior comprimento e massa média dos frutos, além de teores proteicos elevados.

\section{REFERÊNCIAS}

ANDRADE, J. S.; PANTOJA, L.; MAEDA, R. N. Melhoria do rendimento e do processo de obtenção da bebida alcoólica de pupunha (Bactris gasipaes Kunth). Ciência e Tecnologia de Alimentos, Campinas, v. 23, p. 34-38, 2003. Suplemento

AOAC. Official methods of analysis of the Association of Official Analytical Chemists. Washington: Horwitz W, 1997. 850 p.

BERG, R. van den; HAENEN G. R. M. M.; BERG, H. van den; BAST, A. Applicability of an improved Trolox equivalent antioxidant capacity (TEAC) assay for evaluation of antioxidant capacity measurements of mixtures. Food Chemistry, London, v. 66, p. 511-517, 1999.

CARVALHO, A. V.; VASCONCELOS, M. A. M.; SILVA, P. A.; ASCHERI, J. L. R. Produção de snacks de terceira geração por extrusão de misturas de farinhas de pupunha e mandioca. Brazilian Journal of Food Technology, Campinas, v. 12, n. 4, p. 277-284, 2009.

CLEMENT, C. R.; SANTOS, L. A. Pupunha no mercado de Manaus: preferências de consumidores e suas implicações. Revista Brasileira de Fruticultura, Jaboticabal, v. 24, n. 3, p. 778-779, 2002.

CRUZ, C. D. Programa GENES: biometria. Viçosa: UFV, 2006. 452p.
FERREIRA, C. D.; PENA, R. S. Comportamento higroscópio da farinha de pupunha (Bactris gasipaes). Ciência e Tecnologia de Alimentos, Campinas, v. 23, p. 251-255, 2003.

GODOY, H. T.; RODRIGUEZ-AMAYA, D. B. Occurrence of cis-isomers of provitamin A in Brazilian fruits. Journal of Agricultural and Food Chemistry, Washington, v.42, p.1306-1313, 1994.

GOERING, H. K.; VAN SOEST, P. J. Forage fiber analysis (Apparatus, reagents, procedures and some applications). Washington: Agricultural Research Service, 1970.

HASSIMOTTO, N. M. A.; GENOVESE, M. I.; LAJOLO, F. M. Antioxidant activity of dietary fruits, vegetables, and commercial frozen fruit pulps. Journal of Agricultural and Food Chemistry, Washington, v. 53, p. 2928-2935, 2005.

OLIVEIRA, A. N.; OLIVEIRA, L. A.; ANDRADE, J. S.; CHAGAS-JÚNIOR, A. F. Produção de amilase por rizóbios, usando farinha de pupunha como substrato. Ciência e Tecnologia de Alimentos, Campinas, v. 27, n. 1, p. 61-66, 2007.

SANTOS, R. P.; CRISTO-ARAÚJO, M.; PICANÇOTODRIGUES, D.; ASTOLFI FILHO, S.; CLEMENT, C. R. Variabilidade genética e fluxo gênico em populações híbridas e silvestres de pupunha acessada com marcadores RAPD. Revista Brasileira de Fruticultura, Jaboticabal, v. 33, n. 4, p. 1200-1208, 2011.

WANG, H.; CAO, G.; PRIOR, R. L. Total antioxidant capacity of fruits. Journal of Agricultural and Food Chemistry, Washington, v. 44, p. 701-705, 1996.

YUYAMA, L. K. O.; AGUIAR, J. P. L.; YUYAMA, K.; CLEMENT, C. R.; MACEDO, S.H.M.; FÁVARO, D. I. T.; AFONSO, C.; VASCONCELLOS, M. B. A.; PIMENTEL, S. A.; BADOLATO, E. S. G.; VANNUCCHI, H. Chemical composition of the fruit mesocarp of three peach palm (Bactris gasipaes) populations grown in Central Amazonia. International Journal of Food Science and Nutrition, Oxfordshire, v. 54, p. 49-56, 2003.

YUYAMA, L. K. O.; COZZOLINO, S. M. F. Efeito da suplementação com pupunha como fonte de vitamina A em dieta: estudo em ratos. Revista de Saúde Pública, São Paulo, v. 30, n. 1, p. 61-66, 1996. 